\title{
Delayed Myelopathy After Trivial Neck Injury in a Patient With a Cervical Neurenteric Cyst
}

\author{
Rajiv Midha, Bruce Gray, Laurence Becker and James Drake
}

\begin{abstract}
Background: Neurenteric cysts are rare spinal lesions of congenital origin. They usually present insidiously with a long history of local spinal pain, radiculopathy and myelopathy. We report a 14-year-old male with a high cervical neurenteric cyst who developed a progressive myelopathy after minor neck trauma. Full recovery followed a partial cyst excision and decompressive procedure. Significance and conclusion: The possible pathogenic mechanisms for this unusual presentation include hemorrhage into the cyst, sudden mechanical compression from abnormal spinal movement of a chronically distorted and compressed spinal cord, or an increase in the size of the cyst secondary to accumulation of cyst fluid. In this case a small increase in the cyst size may have resulted in increased mechanical distortion and spinal cord dysfunction on a compressive and ischemic basis.
\end{abstract}

\begin{abstract}
RÉSUMÉ: Myélopathie tardive après un traumatisme cervical anodin chez un patient porteur d'un kyste neurentérique. Introduction: Les kystes neurentériques sont des lésions spinales rares d'origine congénitale. Le mode de présentation est insidieux, le patient présentant souvent une longue histoire de douleur spinale locale, de radiculopathie et de myélopathie. Nous rapportons le cas d'un adolescent de 14 ans, porteur d'un kyste neurentérique cervical haut, qui a développé une myélopathie progressive après un traumatisme cervical mineur. La récupération a été complète suite à une excision partielle du kyste et à une décompression. Conclusions: Les mécanismes pathogéniques possibles de ce mode de présentation inusité sont l'hémorragie intrakystique, une compression mécanique subite d'une moelle épinière déformée et comprimée de façon chronique à la suite d'un mouvement anormal, ou une augmentation de la taille du kyste secondaire à l'accumulation de liquide dans le kyste. Une légère augmentation de la taille du kyste peut avoir causé une déformation mécanique plus importante et une dysfonction de la moelle épinière due à la compression et à l'ischémie.
\end{abstract}

Can. J. Neurol. Sci. 1995; 22: 168-171

Neurenteric cysts are broadly defined as cysts that are lined by gastrointestinal mucosa and are in direct contact with the central nervous system. Associated congenital vertebral anomalies are frequently present and, along with the occasional gut and spinal cord anomalies, attest to a congenital basis for the lesion early in embryogenesis when there is a temporary direct connection between the precursors of the spinal cord, spine and gastrointestinal tract. ${ }^{1.2}$ Hence, persistence of the neurenteric canal with a resulting split notochord is theorized. ${ }^{3}$ An alternative hypothesis is that enterogenous cysts are one end of a spectrum of teratomatous cysts, resulting as a misplacement of multipotential germinal cells. ${ }^{4,5}$ The varying nomenclature and controversies regarding their genesis have been recently reviewed. ${ }^{6}$

In the literature, enterogenous cysts are infrequently reported lesions. They are typically intradural spinal lesions, with the greatest frequency in the cervical region, but they occur in any part of the spine and infrequently involve the posterior fossa. The cyst is usually ventral to the neuroaxis, with varying degrees of lateral and posterior extension and spinal cord compression. They typically present with spinal pain, radiculopathy and myelopathy. ${ }^{2}$ The peak age of presentation is in the first two decades with the majority of patients under the age of forty and a 3:1 preference for males over females. ${ }^{7}$ The purpose of this report is to highlight the unusual precipitation of neurologic dysfunction by minor spinal trauma in a patient with a cervical enterogenous cyst and to discuss the possible mechanisms involved.

\section{Case Report}

\section{Clinical}

A 14-year-old left handed male, a grade 9 high school student and high achievement athlete, presented with a delayed myelopathy after minor neck injury.

Four days prior to referral, he slipped at a skating rink, striking the back of his head on the ice. There was no loss of consciousness, although he was momentarily confused. He was able to resume hockey practice after a few minutes. There was mild posterior neck discomfort

From the Department of Surgery (Neurosurgery) (R.M. J.D.), Neuroradiology (B.G.) and Neuropathology (L.B.). Hospital for Sick Children, University of Toronto, Toronto RECEIVED SEPTEMBER 30, 1994. ACCEPTED IN FINAL FORM JANUARY 2, 1995.

Reprint requests 10: Dr. Jim Drake, Division of Neurosurgery, Hospital for Sick Children. 555 University Avenue, University of Toronto, Tononto. Ontario, Canada M5G IX8 
on the night of injury. Over the next three days, a slowly worsening right hemiparesis developed. This was associated with some increase in his neck pain. On the day of referral, he noted urinary hesitancy, decreased flow and cessation of urination in mid-steam.

The patient had an unremarkable past medical history and was considered in excellent physical condition. Indeed, he was enrolled in a special provincial sports program for athletes demonstrating outstanding sports potential. Although he played contact sport (ice hockey) competitively, there was no significant prior history of trauma to the spine, spinal pain, or neurological dysfunction. The family history was negative for congenital, spinal or neurological conditions.

General examination revealed a muscular athletic adolescent. The blood pressure and heart rate were normal. His posterior neck was slightly tender to palpation in the mid-cervical area, but demonstrated no swelling nor bruising. Motor examination disclosed right upper and lower extremity weakness, with decreased power (MRC 3-4/5), most prominent distally in the intrinsic muscles of the hand. Motor power on the left side was normal. Tone was increased in the right leg and sustained ankle clonus could be elicited. Myotactic reflexes were brisker on the right: biceps, triceps and brachioradialis $3+$ on right and $2+$ on left; knee and ankles $4+$ on right and $3+$ on left. Bilateral positive Babinski response were present. Sensory findings were limited to decreased pinprick and light touch in both arms, confined to the C5 dermatome, and more pronounced on the right side. Vibration sensation and proprioception were preserved. He had normal anal tone and was able to void spontaneously. In summary, the neurological examina-

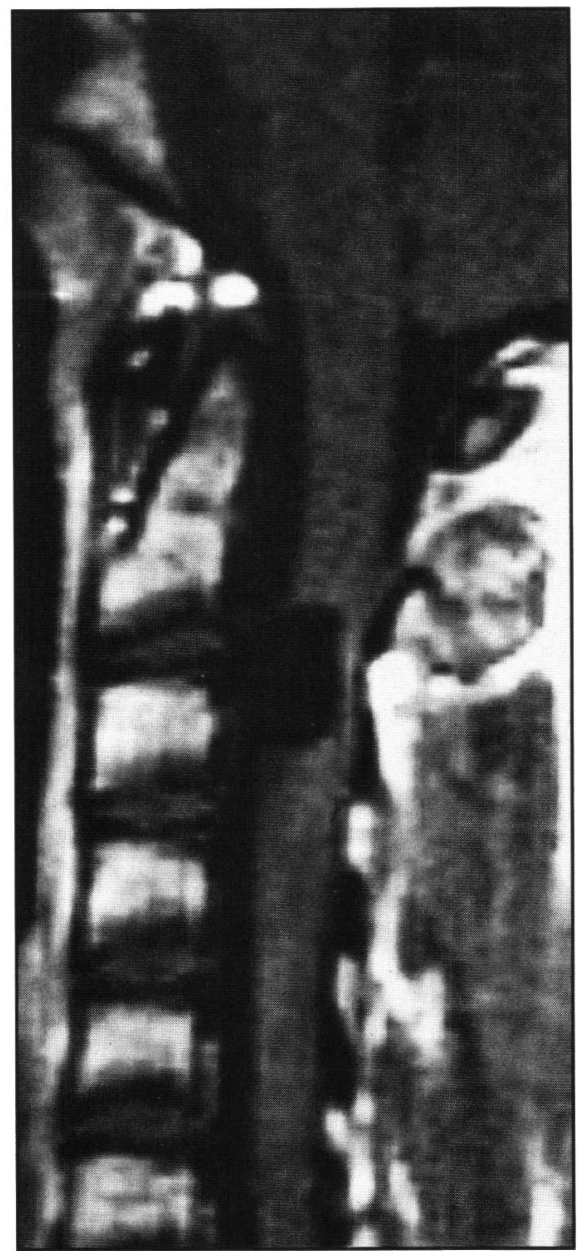

Figure 1: Mid-sagittal TI weighted (spin echo 600/l0) magnetic resonance images through the upper cervical cord demonstrates an intradural lesion which has its epicenter in the C2-3 region. The appearance is that of a cystic mass lesion with signal characteristics which are isointense to CSF. It is primarily ventral to the spinal cord, which it indents and severely compresses. tion disclosed a partial right Brown-Sequard syndrome with a C5 spinal level.

\section{Imaging}

Plain cervical spine films, including lateral, anteroposterior and odontoid views failed to reveal any abnormality. This prompted an emergency magnetic resonance imaging (MRI) study (Siemans, Magnetom, 1.5 Tesla). This showed a large intradural, extramedullary cystic lesion in the spinal canal extending from $\mathrm{Cl}$ to $\mathrm{C} 4$, with its greatest dimensions adjacent to the $\mathrm{C} 2$ and $\mathrm{C} 3$ vertebral bodies (Figures 1 and 2). The lesion was ventral and laterally to the right in relation to the spinal cord, causing marked compression and displacement of the cord, especially adjacent to $\mathrm{C} 2-3$ (Figure 1). The lesion was of a similar intensity to CSF on both T1-weighted (spin echo 600/10) and T2weighted (spin echo 2200/90) imaging sequences (Figures $I$ and 2). It failed to demonstrate enhancement with intravenous gadolinium-DTPA administration.

\section{Operation}

The patient was taken to the operating room upon completion of the MRI. After awake bronchoscopic intubation, and Mayfield pin head fixation, he was turned prone and while awake, positioned, neurologically examined and then anaesthetized. A cervical laminectomy from $\mathrm{C} 2-4$ was performed. The paraspinal muscles and ligaments appeared non-traumatized. The ligamentum flavum and dura were extremely taut. An ultrasound guided aspiration of the intradural cyst was performed, yielding 5 $\mathrm{ml}$ of clear fluid without any trace of blood. This inmediately slackened the dura, which was opened under the operating microscope. The cyst was ventrolateral on the right, displacing the spinal cord dorsal and lateral to the left. The cyst wall was thin and translucent. This lining was septated in many places and quite adherent to the inner surface of the dura and the spinal cord. An excision and wide fenestration of the cyst was performed, removing the great majority of the lining, except for adherent material on the ventral surface of the cord. This nicely decompressed the cord, which then assumed a more normal position. A cysto-subarachnoid shunt was then placed from the residual cyst cavity to the dorsal surface of the cord traversing the area of mobilized dense adhesions.

\section{Pathology}

Microscopically the lining epithelium varied from to low to high columnar beneath which was a basement membrane and connective

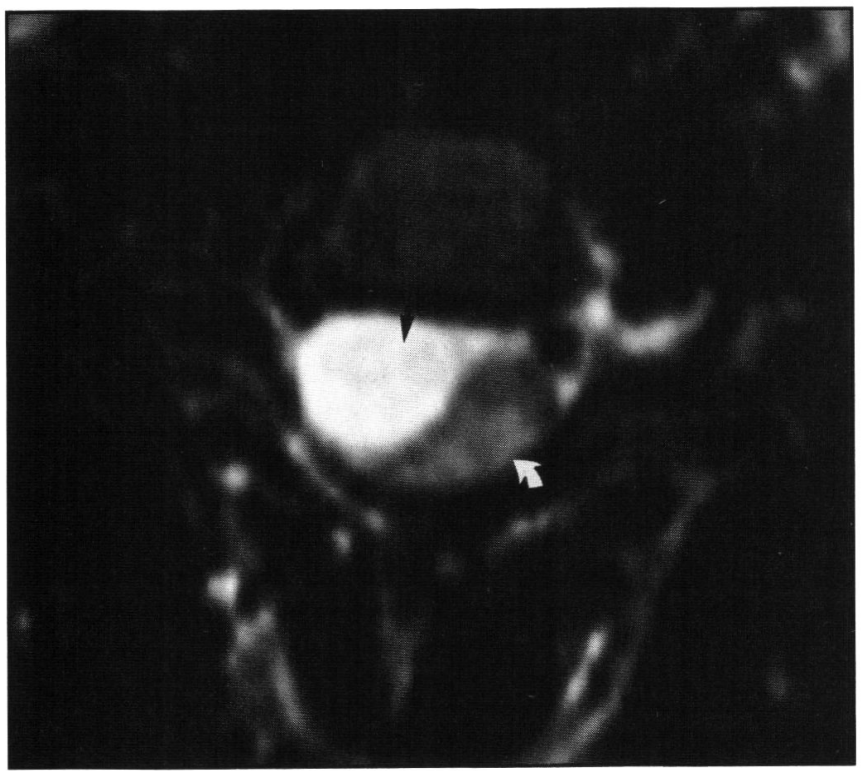

Figure 2: Axial T2 weighted (spin echo 2200/90) magnetic resonance image at the level of the C3 vertebral body. A large intradural. extramedullary cystic lesion (black arrow) is seen ventrolateral to the right in relation to the spinal cord (curved white arrow). The lesion demonstrates T2 signal intensity similar to CSF. It displaces the spinal cord posteriorly and to the left. 


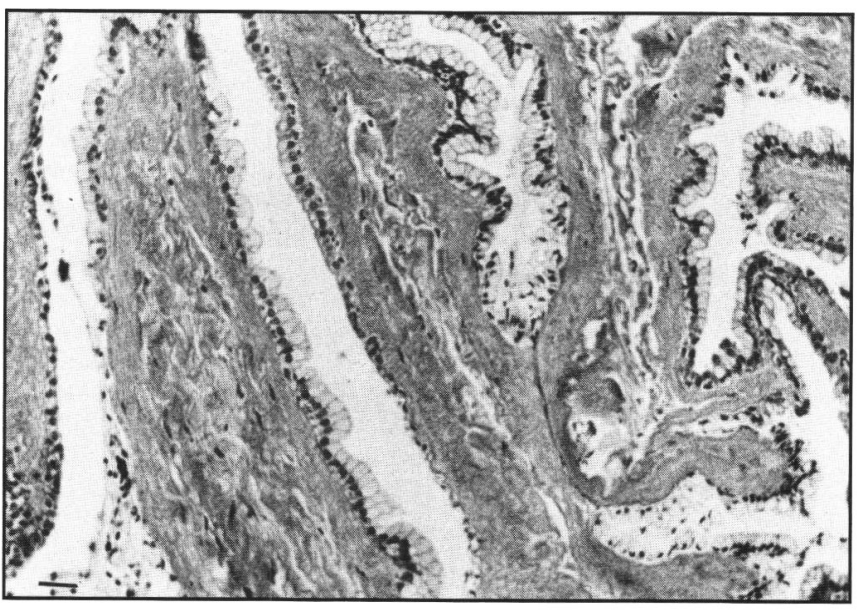

Figure 3: Photomicrograph of histologic section of the cystic lesion. An epithelial lining of columnar cells and Goblet cell rests on an avascular and poorly cellular connective tissue stroma (Masson's trichrome stain, $X$ 175; scale bar $20 \mathrm{um}$ ).

tissue stroma (Figure 3). Present in the lining were numerous mucin secreting (Periodic acid-Schiff-positive) Goblet cells. No cilia or squamous metaplasia were identified. Hemorrhage was not evident in the cyst wall. The histologic features of a mucin secreting columnar epithelium are characteristic of a neurenteric cyst.

\section{Post-operative and follow-up:}

The patient experienced an uneventful post-operative course. There was progressive recovery in his right hemiparesis and he could ambulate on the second post-operative day. Urinary symptoms disappeared post-operatively. Six weeks after surgery, neurological examination showed no detectable weakness and only subtle reflex asymmetry. On follow-up at 6 months, the patient remained asymptomatic and MRI demonstrated collapse of the cyst with re-expansion of the spinal cord. However, approximately 1 year post-operatively, the patient developed a myelopathy, with clinical and imaging features very similar to his first presentation. This led to a repeat decompressive procedure including a gross total removal of the cyst lining. The patient is clinically normal 3 months after the second operation.

\section{Discussion}

Based on a literature review of 47 cases reported from 1926 to 1972 , Wilkins and Odom noted the clinical presentation of a neurenteric cyst in most cases to be that of a chronic myelopathy. ${ }^{2}$ Pain in the affected spinal region, occasionally accompanied by radiculopathy, preceded a gradual onset and variable progression of spinal cord dysfunction. The myelopathy was usually prolonged over months and years and marked by exacerbations and remissions before a diagnosis was made. ${ }^{2} \mathrm{~A}$ survey of these early cases reveals that in some instances, the deterioration of the patient was related to minor trauma. ${ }^{8-10}$ In subsequent case reports, additional examples of the beginning or the worsening of clinical features after minor trauma, ${ }^{6}$ Valsalva maneuvers, such as coughing and sneezing, ${ }^{11}$ or manipulative procedures $^{12}$ were also noted. Other types of spinal cystic lesions, such as arachnoid cysts, have presented with subacute myelopathy, apparently precipitated by iatrogenic trauma. ${ }^{13}$

Adams and Wegner in 1947 had first emphasized the intermittent symptomatology related to spinal cord compression with cystic lesions. ${ }^{8}$ They reported two patients with neurenteric cysts, each of whom over several years had at least five separate discrete episodes of spinal pain followed by a subacute myelopathy, and then gradual recovery. Their second case bears some striking resemblance to our subject, as he developed spinal pain and then a profound myelopathy with findings consistent with a partial Brown-Sequard syndrome, shortly after a fall down stairs. The authors did not invoke a causal relationship between the symptoms and his minor trauma. Amongst their proposed mechanisms for the periodic relapse and recurrence of the symptoms included fluctuations in the formation and reabsorption of mucin by the cyst wall, periodic rupture of the cyst and increase in the cyst size secondary to local hemodynamic and osmotic factors.

In addition to the theories advanced by Adams and Wegner, the onset or worsening of neurologic symptoms experienced by patients harboring spinal cord cysts after minor trauma may be related to several other mechanisms. The first mechanism may be hemorrhage into the cyst. Alternatively, sudden mechanical compression, from abnormal spinal movement, of a chronically distorted and compressed spinal cord may be responsible. The injury caused to the cord in the latter situation may be mechanical, ischemic or a combination of the two. Additionally, an increase in the size of the cyst secondary to increased accumulation of cyst fluid is also possible, especially in cases related to exacerbation by Valsalva maneuvers, reminiscent of the clinical deterioration seen in patients with syringomyelia. Could an alteration in flow dynamics between the CSF space and the cyst cavity, favoring accumulation of fluid within the cyst, be similarly engendered by trauma? Finally, a purely coincidental relationship between the minor injury and clinical worsening in patients harboring a spinal cyst cannot be discounted.

In the present case, the onset of symptoms were clearly related to a minor flexion neck injury. Worsening pain and a progressive myelopathy developed over three days. Of significance is that the patient was neurologically intact immediately after and for approximately 24 hours following the trauma. The cyst contained clear fluid, without any discernible hemorrhage. There was no visible bruising of the cyst wall or spinal cord and lack of hemorrhage on pathological exam of the cyst wall. Collectively, this information excludes hemorrhage into the cyst as a possible event in the pathogenesis of the patients deterioration. It also casts doubt on an acute mechanical compression at the time of injury as being the pathophysiologic mechanism. Instead, the delayed and progressive neurological deterioration suggests a more dynamic process. One possibility is progressive cyst expansion and cord compression, perhaps related to altered fluid dynamics, with accumulation of CSF and/or cyst fluid. A second explanation is progressive ischemia and therefore dysfunction of an already compromised spinal cord by an event that increased the compression only incrementally, but to a threshold level that impaired the local microcirculation. The concept of threshold is supported by the clinical features of a partial Brown-Sequard syndrome in the present case, with a hemiparesis evolving on the side of the chronic compression.

In summary, intraspinal congenital cysts may occasionally present with a rapid onset and quick progression of myelopathy after a minor spine injury. This is well illustrated in the present case and has been previously documented, but not well appreciated, in the literature. We speculate that a small increase in the cyst size secondary to the trauma results in increased mechanical distortion and spinal cord dysfunction on a compressive and ischemic basis. This case also serves to emphasize the value of prompt imaging, 
ideally with MRI, to search for an underlying spinal lesion in any patient manifesting myelopathy after a trivial injury.

\section{ACKNOWLEDGEMENT'S}

Presented in part at the Canadian Congress of Neurosciences, St. John's, Newfoundland, June, 1994.

\section{REFERENCES}

1. Veeneklass GMH. Pathogenesis of intrathoracic gastrogenic cysts. Am J Dis Child 1952; 83: 500-507.

2. Wilkins RH, Odom GL. Spinal intradural cysts. In: Vinken PJ, Bruyn GW, ed. Handbook of Clinical Neurology, vol. 20, Tumors of the Spine and Spinal Cord, Part II. Amsterdam: North Holland, 1976: 55-102.

3. Bentley JFR, Smith JR. Developmental posterior enteric remnants and spinal malformations. The split notochord syndrome. Arch Dis Child 1960; 35: 76-86.

4. Rewcastle NB, Francouer J. Teratomatous cysts of the spinal canal. With "sex chromatin" studies. Arch Neurol 1964; 11:91-99.
5. Rosenbaum TJ, Soule EH, Onofrio BM. Teratomatous cysts of the spinal canal. Case report. J Neurosurg 1978; 49: 292-297.

6. Breeze RE, Nichols P, Segal H, et al. Intradural epithelial cyst at the craniovertebral junction. J Neurosurg 1990; 73; 788-791.

7. Wilkins RH. Intraspinal cysts. In: Wilkins RH, Rengachary SS, eds. Neurosurgery. New York: McGraw-Hill, 1985: 2061-2070.

8. Adams RD, Wegner $W$. Congenital cysts of the spinal meninges as cause of intermittent compression of the spinal cord. Arch Neurol Psychiatry 1947; 58: 57-69.

9. Scoville WB, Manlapaz JS, Otis RD, et al. Intraspinal enterogenous cyst. J Neurosurg 1963; 20: 704-706.

10. Dorsey FD, Tabrisky J. Intraspinal and mediastinal foregut cyst compressing the spinal cord. Report of a case. J Neurosurg 1966: 24: $562-567$.

11. Guilburd JN, Ben Arieh Y, Peyser E. Spinal intradural enterogenous cyst: report of a case. Surg Neurol 1980; 14: 359-362.

12. Fabinyi GCA, Adams JE. High spinal cord compression by an enterogenous cyst. J Neurosurg 1979; 51 : 556-559.

13. Valls PL, Naul LG, Kanter SL. Paraplegia after a routine lumbar laminectomy: report of a rare complication and successful management. Neurosurgery 1990; 27: 638-640. 